\title{
A PHYSICS SHOW PERFORMED BY STUDENTS FOR KIDS: From Mechanics to Elementary Particle Physics 1
}

\author{
Herbi K. Dreiner \\ Physikalisches Institut, Universität Bonn \\ Nußallee 12, 53115 Bonn, Germany \\ February $1^{\text {st }}, 2007$
}

\begin{abstract}
In this article, we describe an initiative at the University of Bonn, where the students develop and perform a 2 hour physics show for school classes and the general public. The show is entertaining and educational and is aimed at children aged 10 and older. For the physics students this is a unique experience to apply their knowledge at an early stage and gives them the chance to develop skills in the public presentation of science, in front of 520 people per show. We have extended the activity to put on an elementary particle physics show for teenagers. Furthermore, local high schools have picked up the idea; their students put on similar shows for fellow students and parents. We would be interested in hearing about related activities elsewhere.
\end{abstract}

Physics students spend the early part of their training attending physics and mathematics lectures, solving problem sets and experimenting in laboratory courses. The program is typically intensive and fairly rigid. They have little opportunity to follow their own curiosity or apply their knowledge. There have been several attempts to address this deficiency. For example, Prof. Clint Sprott at the University of Wisconsin, where the author was a graduate student, hosts a physics show entitled "The Wonders of Physics." (The show has continued since 1984, http://sprott.physics.wisc.edu/wop.htm). Dressed up as a mixture of circus director and magician and assisted by students, Prof. Sprott presents entertaining and educating experiments to a regularly packed audience of all age groups [1]. This was in turn inspired by the "Chemistry is Fun" presentations of Prof. Basam Shakhashiri, also from the University of Wisconsin (http://scifun.chem.wisc.edu/).

In 2001, we launched a similar activity in Bonn. Our idea was to give a group of undergraduates (about 25-30) from every incoming class (about 150-170) the opportunity to put on a physics show for kids aged 10 and older. Thus the essential point of this initiative is that the students develop and perform the show themselves; it is entirely in their control. The students have full access to our collection

\footnotetext{
${ }^{1}$ The following article has been submitted to The Physics Teacher. After it is published, it will be found at http://scitation.aip.org/tpt/.
} 
of demonstration experiments, assisted and advised by Michael Kortmann, who is in charge of the collection. They also receive assistance from our workshops in the development and construction of new experiments. They can thus follow their own curiosity, choosing the experiments they find interesting. They spend many hours understanding the experiments and considering how to best explain them to children, without oversimplifying. The show is a unique opportunity for the students to apply their knowledge at an early stage by teaching kids in a dramatic environment and to develop valuable skills in the public presentation of science. The show has been a resounding success with the public, with a regularly packed 520-people auditorium. For us however, the Bonn physics show is first and foremost an educational tool addressed at our physics students [2]. The enthusiasm with which they have picked up the idea has more than rewarded our efforts, and their talent at public presentation is a delight to observe. Furthermore, we now have a very large pool of experienced and enthusiastic students with whom we have developed further outreach activities. For example, we participate in the so-called Bonn Science Night. This is a science fair organized every other year in the main university builing, an 18th century palace. This effort was initiated and organized entirely by the students themselves.

Every year in January, we recruit a new group of students in the second year class. The students participate voluntarily and for no credit. Together with students from previous years, Michael Kortmann and I attend the initial meetings. We pass on our experience and give the main idea of how the show is set up. Starting in March, the students largely organize the meetings themselves. The last 8-10 days before the first show, the students rehearse daily. Michael Kortmann gives technical assistance and students from previous years and I give advice on the text and presentation. There are three performances in September and a repeat with three more at the end of February. One performance is always for school classes (coming from as far as $100 \mathrm{~km}$ ) and two on the weekend are for the general public.

The show lasts two hours, including a 20 minute intermission, when the children can try out and have a close look at experiments at the front of the lecture hall, as well as in the extensive lobby. There are two MC's (one woman and one man) to guide the audience through the show. Two important ingredients were introduced by the students in the first year. (i) Short $(<90 \mathrm{sec})$ home-made entertaining movies to introduce the various physics topics (e.g. mechanics, magnetism, lowtemperatures) into which the show is divided. Over the years these have become quite elaborate. They can be viewed at http://www.physikshow.uni-bonn.de/ (ii) Between explanations, the experiments are accompanied by up-beat music, which creates a unique energetic atmosphere, very much appreciated by the young audience and the local radio station, which has twice broadcast live from the show. 
Two weeks ago we started putting the introductory films, as well as films of experiments on YouTube. The most successful film shows a light boat built out of aluminum foil floating in an aquarium filled with sulphur hexafluoride, Fig. 1. Within the first 3 weeks it had over 290,000 viewings, making it the fourth most viewed German science and technology film "all time". The film can be viewed at http://www.youtube.com/watch?v=1PJTq2xQiQ0. Some trailers can also be viewed on YouTube under the search words "Physikshow" and "Bonn". One film, for example, shows momentum conservation with a multiple pendulum followed by four test car crashes all to Beethoven's $9^{\text {th }}$ symphony, Beethoven of course originating from Bonn. Another film shows ball bearings bouncing in a simulation of kinetic gas theory, followed by a sequence of photos relating to atomic and particle physics, accompanied by upbeat music.

Over the years the students have built quite a few experiments themselves. It started with a simple apparatus to let pickles and other vegetables glow, when an electrical current flows through them. Later, these included a hoover craft with a chair and a vacuum cleaner engine, a superconducting train, the "Polar express", which is shown in Figs. 2 and 3, and a large tank to simulate a tsunami wave. The students also built a large box $\left(\sim 2 \mathrm{~m}^{3}\right)$ which produces smoke rings which travel through the entire lecture hall.

This is the basic structure of the show into which the students have introduced a tremendous variety. The first two years, the show was similar to those of Prof. Sprott: a series of experiments were presented and explained. In the third year, the students developed a question and answer scheme, where one of the MC's asked questions and the other explained the physics. This created a better flow and also dramatically improved the explanations, since the students had to imagine possible questions the kids might have. In the fourth year, the students built a "time-travel machine" out of an old telephone booth and a smoke machine, and the two MC's visited the Stone Age, Aristotle, Newton, etc. asking questions directly of the greats. Last year the students staged the entire physics show as a large computer game, where they had to solve various physics problems to advance to higher levels. For the movies the two protagonists wandered through a virtual computer world to advance to the next level.

The physics show has mainly involved classical physics occasionally with some quantum effects. However, when the particle physics laboratory CERN turned 50 in 2004, the first year group had sufficiently advanced in their studies that we could put on an elementary particle physics and cosmology show addressed at high-school students. This was a huge success with the local schools.

In March, 2006, we were honored that the Deutsche Museum, in München, in- 
vited us to put on three shows in the distinguished Ehrensaal, something like the hall of fame of German science and technology. This was an exciting opportunity for the students and our first big away game. It was also a logistical challenge to get the experiments to München at a reasonable cost. The performances were very well received and the Museum has suggested turning this into a semi-annual event.

The basic idea of the physics show also carries over to high-school physics. Two local high-schools have independently put on shows for their fellow students and their parents. At the Kollegium Josephinum, the students put on a 60 min show on the topic of "water". At the school in Hennef, they have a regular group called the "Physikusse", which also puts on small shows. (http://www.ge-hennef.de/foefo/ begabung_physikusse.htm)

In October, 2006, in honor of the tremendous amount of effort the students have put into the physics show, they received the Alumni Prize of the University of Bonn for student initiative.

\section{Acknowledgments}

It is a great pleasure to thank Michael Kortmann. We have been pursuing this project jointly from the beginning and it has always been an honour to work with him. Furthermore, I would like to thank our secretaries Patricia Zündorf, Dagmar Fassbender and Sandra Heidbrink for their support and their efforts way beyond the call of duty. Most of all I would like to thank the students of the past five years for the great fun and enthusiasm they have brought to the Physikshow.

\section{References}

[1] C.J. Sprott, Phys. Teach. 29, 212 (1991)

[2] In the German university system physics students only have classes in physics and mathematics as well as a small minor requirement such as chemistry or astronomy. The level they have reached after three years is typically considered equivalent to an American bachelor degree. Furthermore, they graduate from high-school a year later and the men typically have one year of military or community service. They are therefore also on average one and a half years older at the same stage. 


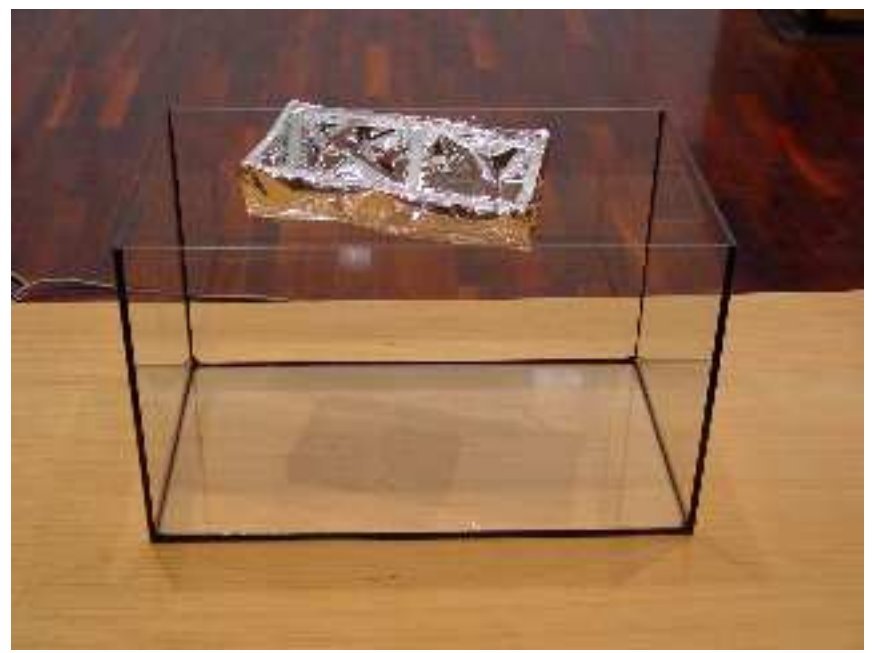

Fig. 1 Aluminium boat floating on sulphur hexafluoride

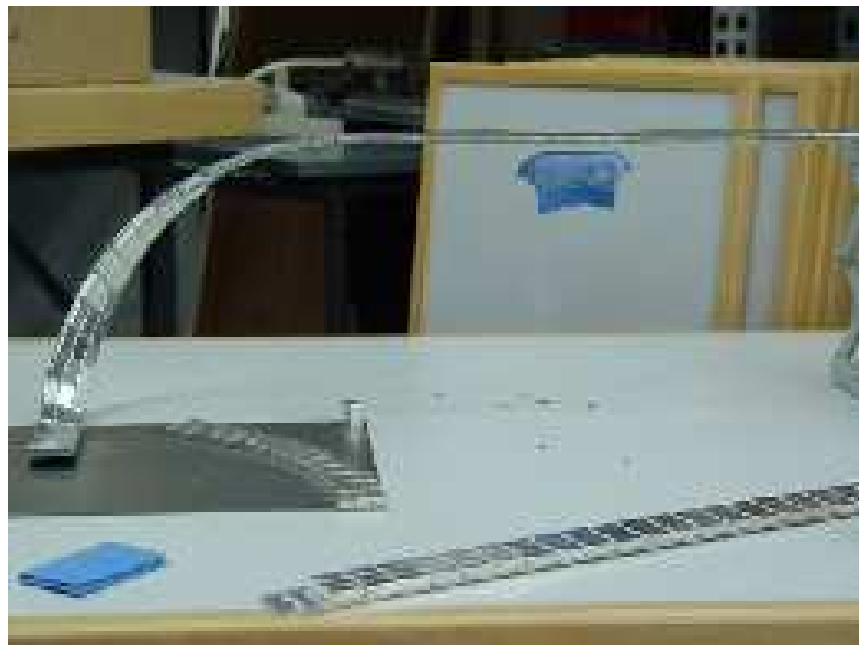

Fig 2. Superconducting train, construction phase, with a blue suspended "train". 


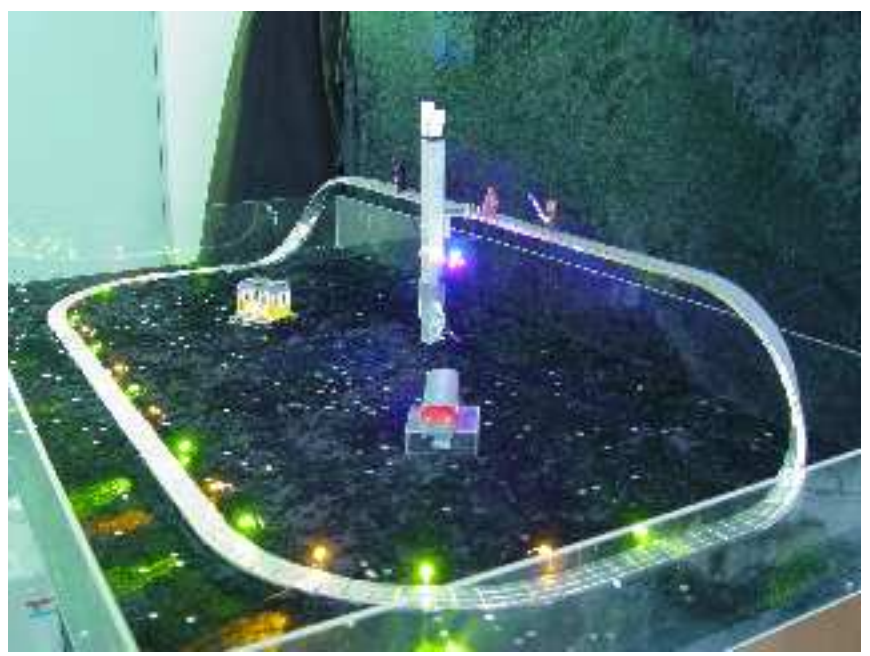

Fig. 3 Superconducting train set with lighting and gondola trains. 